\title{
KRAS NM_004985.3:c.37_38delGGinsAA
}

National Cancer Institute

\section{Source}

National Cancer Institute. KRAS NM 004985.3:C.37 38delGGinsAA. NCI Thesaurus. Code C98413.

A complex substitution where the nucleotide sequence at positions 37 through 38 of the coding sequence of the KRAS gene has changed from guanine-guanine to adenineadenine. 